\section{Perception of mineral character in Sauvignon blanc wine: inter-individual differences}

\author{
Wendy Veronica Parr, ${ }^{1}$ Jordi Ballester, ${ }^{2}$ \\ Dominique Peyron, ${ }^{2}$ Claire Grose, ${ }^{3}$ \\ Dominique Valentin ${ }^{2}$ \\ 'Department of Wine, Food \& Molecular \\ Biosciences, Lincoln University, New \\ Zealand; ${ }^{2}$ CSGA - UMR5170 - CNRS, \\ Université de Bourgogne, Dijon, France; \\ ${ }^{3}$ Institute of Plant and Food Research, \\ Marlborough, New Zealand
}

\section{Abstract}

Of the descriptors employed to characterize wine organoleptically, minerality is arguably one of the most enigmatic. The aim of the work described in this article was to delineate the nature of perceived minerality in Sauvignon wine, specifically its sensorial reality for experienced wine professionals from France and New Zealand. Participants evaluated 16 Sauvignon blanc wines (8 French; 8 New Zealand) under three conditions, ortho-nasal olfaction, palate only (Nose-clip condition), and by full tasting (global perception). Data from the global condition only are reported here. Key results include: i) that although there were quantitative differences in perception of minerality as a function of culture, there was substantial agreement conceptually between French and New Zealand participants in terms of the sensorial experience of minerality; and ii) that perceived minerality associated significantly with other key wine descriptors, notably presence of citrus, stone-related characters (e.g., flinty or chalky/calcareous notes), and reductive notes, along with absence of Sauvignon varietal characteristics (passion fruit; green notes). Of particular interest, no significant, direct association was found between perceived sourness/acidity and minerality judgments for either culture.

\section{Introduction}

Sensory science can be considered as a nexus in multi-disciplinary wine research, serving as a junction that brings together phenomena from viticultural, oenological, and marketing/cultural research. This is most pronounced when abstract wine characteristics such as quality and complexity are investigated scientifically. Minerality in wine is one such enigmatic and elusive perceived characteristic that recently has come under scientific scruti- ny. Despite its ill-defined nature, wine producers and wine critics increasingly use the term, ${ }^{1}$ linking perceived mineral characteristics with wine quality.

Historically, perceived minerality has been associated with terroir or source-of-origin of a wine, this association functioning as a powerful marketing tool for many of the world's more expensive wines. However, recent and convincing argument that application of the term mineral to wine sensory attributes is metaphorical has been put forward by geologist Alex Maltman. ${ }^{2}$ Maltman presents data to demonstrate that it is unlikely that there is a direct link between soils and other aspects of vineyard geology and perception of mineral characteristics in wine. This leaves open the question as to what people are smelling and tasting in wine that results in verbal reports describing their sensory experience in terms of rocks, wet stones, soils, and so forth. One explanation offered for the association of perceived minerality with wine source-of-origin involves wine acidity, with qualitative and quantitative aspects of acidity in wine linked to terroir variables such as soil $\mathrm{pH}{ }^{3}$ Several other hypotheses have been put forward concerning the relation between perceived minerality in a wine and the wine's chemical and sensory characteristics. One that has gained attention implicates perception of minerality in wines from New World countries that employ inert bottle closures as having its basis in sulphide reduction. Another potential source of perceived minerality in wine is the sensory context created by relative absence of perceived flavour such as fruity or vegetal characteristics. We investigated several hypotheses with the aim of understanding the sensorial reality of perceived minerality.

Given the metaphorical nature of perception of minerality, and hence involvement of psychological phenomena such as associative memory and language (e.g., in perception and verbal labelling of a wine as expressing chalky or flinty notes), the influence of a taster's culture and hence domain-specific, experiential history is relevant. We investigated influence of culture on perception and judgment of mineral character in Sauvignon wine, with French (Old World) and New Zealand (NZ) (New World) participants in the sensory study. Based on the assumption that perception of minerality in wine involves multi-modal sensory input a second independent variable investigated was mode of perception: study participants evaluated the wines by i) ortho-nasal olfaction alone; ii) olfaction, taste and trigeminal stimulation (global perception); and iii) palate sensations alone (nose-clip condition: taste and trigeminal sensations). Data from the global perception condition only are reported in this article.
Correspondence: Wendy Veronica Parr Department of Wine, Food \& Molecular Biosciences, Lincoln University, Lincoln 7647, New Zealand.

Tel./Fax: +64.35256223.

E-mail: wendy.parr@lincoln.ac.nz

Key words: sensory, minerality, Sauvignon blanc

Contributions: WVP, substantial contribution in terms of conception and design of the study, conduction of the empirical component in New Zealand, drafting the initial written version of Introduction and Methods (New Zealand component), revision of Results and Discussion, data analysis interpretation and revision of intellectual content; JB, substantial contribution in terms of conception and design of the study, conduction of empirical component in France, initial draft of Methods (French component), data analysis and interpretation; DP, substantial contribution in terms of conception and design of the study and conduction of empirical component in France; CG, substantial contribution in terms of conduction of the New Zealand empirical component; DV, substantial contribution in terms of conception and design of the study, data analysis and interpretation, drafting initial written version of Results and Discussion, data analysis interpretation, revision of intellectual content. All authors read and approved the final draft of the manuscript.

Presented at the $3^{\text {rd }}$ International Conference on Wine Active Compounds (WAC) - March $26^{\text {th }}-28^{\text {th }}$ 2014, Beaune, France.

Acknowledgements: the research was funded by New Zealand (NZ) Winegrowers, the NZ Ministry for Science and Innovation, Pernod Ricard NZ, and Pernod Ricard Centre de Recherche, Paris, France. We thank wine professionals in France and New Zealand who participated in the study.

Received for publication: 30 June 2014.

Revision received: 17 September 2014.

Accepted for publication: 17 September 2014.

This work is licensed under a Creative Commons Attribution 3.0 License (by-nc 3.0).

(C) Copyright W.V. Parr et al., 2014

Licensee PAGEPress, Italy

Wine Studies 2014; 3:4474

doi:10.4081/ws.2014.4474

\section{Materials and Methods}

\section{Participants}

Wine professionals from $\mathrm{NZ}(\mathrm{N}=31)$ and France $(\mathrm{N}=32)$, each experienced with production and tasting of Sauvignon wines, participated. French professionals participated in one of three regions of France, namely Bordeaux $(\mathrm{N}=10)$, Sancerre $(\mathrm{N}=13)$, and Chablis $(\mathrm{N}=9)$. New Zealanders participated in Marlborough, NZ. 


\section{Wines}

Sixteen 100\% Sauvignon blanc wines from the 2010 vintage were employed in the study, 8 wines from NZ (2 from each of four sub-regions of Marlborough: Southern Valleys; Lower Wairau; Rapaura; Awatere Valley), and 8 wines from the major Sauvignon regions of France (2 from each of Bordeaux; Loire; Sancerre; Saint Bris). Wines were selected as reflecting well their source of origin and vintage according to their producers. The wines ranged in alcohol \% $\mathrm{v} / \mathrm{v}$ between 12.5 and 14. French wines were sealed with cork closures and NZ wines were sealed with screw-cap closures.

\section{Procedure}

In each location, the sensory studies were conducted over two sessions per participant. Wine samples were served blind in standardized, opaque tasting glasses, and in a unique order for each participant according to a Williams Latin Square arrangement. Participants rated 20 scales per wine in each of three conditions (ortho-nasal olfaction only, palate only, and the global tasting condition). The twenty scales included five Sauvignon flavor characteristics (herbaceous; boxwood; citrus; green; passion-fruit), three tastes (sweetness; bitterness; sourness), five characteristics considered as potential descriptions of perceived minerality and/or reductive characteristics (flinty/stony/smoky; chalky; iodine/oyster shell; pencil/graphite; matchstick/burnt rubber/sulphide), and six other wine characteristics (astringency; freshness; concentration; complexity; familiarity; liking).

\section{Data analysis}

Data collected in the global evaluation condition only were analyzed for this article. To evaluate inter-individual differences in minerality ratings we started by standardizing individual minerality scores $(\mathrm{M}=0, \mathrm{Std}=1)$ to compensate for biases in the use of the scales. Then we pooled together the data from NZ and French wine-professional participants and submitted the resulting wine-by-participant matrix to a hierarchical cluster analysis (HCA) with the Ward criteria. To understand the differences between participant clusters yielded by the HCA we computed two-way, mixed design ANOVAs on all 20 scales, with Cluster as a between-subject variable and Wine as a within-subject variable. To understand the criteria used by participants from each cluster, we then performed a multiple regression analysis with mineral as dependant variable and all other descriptors as predictors. Finally, to test the four hypotheses stated in the introduction, we carried out four multiple regressions for each participant cluster, each time using only the descriptors assumed a priori to be related to each hypothesis (Table 1).

\section{Results and Discussion}

\section{Importance of culture as a driver of inter-individual differences}

The HCA performed on the standardized minerality scores (Figure 1) yielded three main clusters. The first cluster (from top to bottom) includes an equal number of French and NZ judges (11 of each). The other two clusters appear somewhat more culture driven. The second cluster includes more French $(\mathrm{N}=12)$ than NZ participants $(\mathrm{N}=6)$ whereas the reverse is observed for the third cluster $(\mathrm{N}=14 \mathrm{NZ} ; \mathrm{N}=7$ French). Whereas, the two-way ANOVAS showed a significant effect $(\mathrm{P}=0.05)$ of wines for all 20 scales, a significant effect of cluster was observed for six descriptors only (mineral; flinty/smoky; chalky/calcareous; complexity; familiarity; and liking). For these six scales, participants in Cluster 3 (more NZ participants) gave on average higher scores than participants in Cluster 1. Participants from Cluster 2 gave intermediary scores for the six scales. This result provides evidence that the main differences between the three clusters correspond to reported intensity of stone-based characters, as well as to judgments of more global or holistic characteristics linked to familiarity and hedonics (liking). No significant interactions were observed between wines and clusters for Sauvignon varietal characteristics except for passion fruit, indicating some differences in the quantitative evaluation of this attribute amongst

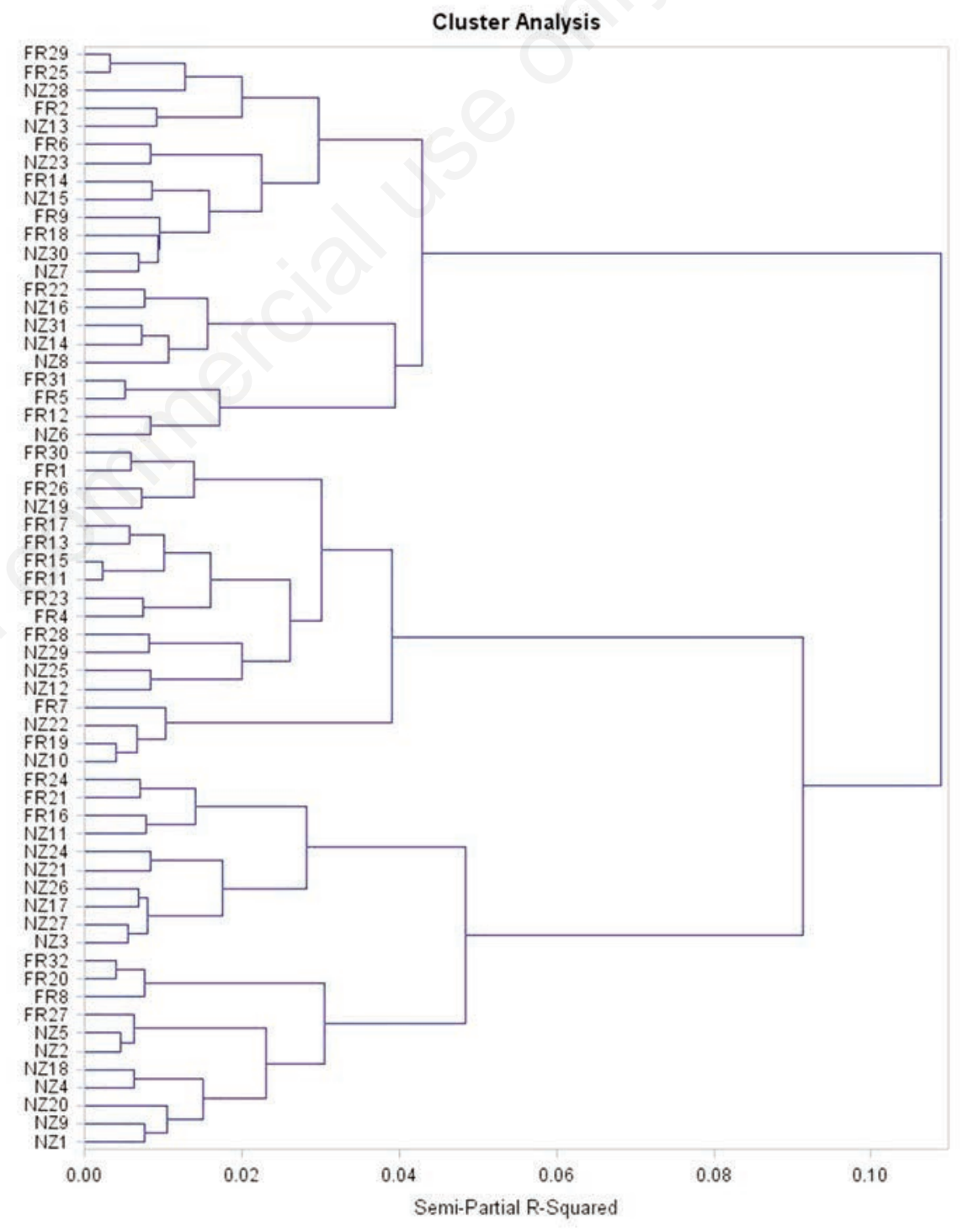

Figure 1. The three main clusters yielded by the hierarchical cluster analysis performed on the standardized minerality scores. 
the three clusters.

With respect to minerality ratings to individual wines (Figure 2), participants from Cluster 1 appear more sensitive to wine origin than do participants from the two other clusters, with French wines in general being rated as less mineral than $\mathrm{NZ}$ wines. Interestingly, this cluster contained an equal number of French and NZ participants. On the other hand, judgments by participants in the two clusters that were dominated by either
French or NZ participants were less wine-origin dependent. Multiple regression analyses carried out separately for each cluster suggest different interpretations of the term minerality as a function of cluster (Table 2). For participants

Table 1. Predictors used in the multiple regression analyses testing each of the four minerality hypotheses presented in the introduction.

\begin{tabular}{|c|c|}
\hline Hypothesis & Predictors \\
\hline $\begin{array}{l}\text { H1: perceived minerality has its basis in perception } \\
\text { of stone/soil-associated descriptors }\end{array}$ & $\begin{array}{c}\text { Chalky/calcareous, iodine/oyster shell, pencil/lead/graphite, } \\
\text { flinty/stony/smoky/gun flint }\end{array}$ \\
\hline $\begin{array}{l}\text { H2: perceived minerality has its basis in perception } \\
\text { of reductive characteristics }\end{array}$ & $\begin{array}{l}\text { Matchstick/struck match/burnt rubber/sulphide, } \\
\text { lead/graphite, flinty/stony/smoky/gun flint, bitterness }\end{array}$ \\
\hline $\begin{array}{l}\text { H3: perceived minerality has its basis } \\
\text { in perception of characteristics related to acidity }\end{array}$ & Acidity/sourness, freshness/zingy, astringency, citrus \\
\hline $\begin{array}{l}\text { H4: perceived minerality has its basis in perceived absence of Sauvignon } \\
\text { varietal flavors (i.e., fruity or vegetal characteristics) }\end{array}$ & $\begin{array}{l}\text { Passion fruit, herbaceous, boxwood, } \\
\text { sweetness, concentration/palate weight }\end{array}$ \\
\hline
\end{tabular}

Table 2. Multiple regression analyses of minerality for the three clusters of participants. The 20 scales are used as predictors.

\begin{tabular}{|c|c|c|c|c|c|c|}
\hline \multirow[t]{2}{*}{ Variable } & \multicolumn{2}{|c|}{ Cluster 1} & \multicolumn{2}{|c|}{ Cluster 2} & \multicolumn{2}{|c|}{ Cluster 3} \\
\hline & $\mathrm{t}$ value & $\operatorname{Pr}>|t|$ & $\mathrm{t}$ value & $\operatorname{Pr}>|t|$ & t value & $\operatorname{Pr}>|t|$ \\
\hline Intercept & 0.96 & 0.3389 & 0.42 & 0.6774 & 1.10 & 0.2736 \\
\hline Herbaceous & 1.83 & 0.0679 & 0.82 & 0.4121 & 1.95 & 0.0526 \\
\hline Boxwood & -0.41 & 0.6827 & 1.57 & 0.1172 & -0.05 & 0.9607 \\
\hline Citrus & 2.61 & 0.0095 & 2.62 & 0.0094 & 3.91 & 0.0001 \\
\hline Green & -0.69 & 0.4935 & -1.86 & 0.0635 & -2.39 & 0.0173 \\
\hline Passion fruit & 1.15 & 0.2528 & -1.21 & 0.2271 & -3.06 & 0.0024 \\
\hline Sweet & -3.50 & 0.0005 & -2.88 & 0.0043 & -0.99 & 0.3212 \\
\hline Bitter & 0.16 & 0.8762 & 4.80 & $<.0001$ & -0.59 & 0.5533 \\
\hline Souracid & -0.27 & 0.7866 & -1.51 & 0.1321 & -0.60 & 0.5502 \\
\hline Astringent & -0.29 & 0.7707 & -1.23 & 0.2206 & -0.76 & 0.4489 \\
\hline Fresh-zingy & 1.32 & 0.1882 & 1.65 & 0.0993 & 1.04 & 0.2987 \\
\hline Flinty & 6.71 & $<0.0001$ & 1.18 & 0.2382 & 3.32 & 0.001 \\
\hline Chalky & 3.32 & 0.001 & 1.74 & 0.0837 & 3.38 & 0.0008 \\
\hline Iodine-oyster & -1.09 & 0.2786 & 1.57 & 0.1167 & 0.28 & 0.7813 \\
\hline Lead-graphite & 1.68 & 0.0944 & 1.12 & 0.2631 & 0.09 & 0.9258 \\
\hline Sulphide & 0.02 & 0.9816 & 0.03 & 0.9774 & 1.03 & 0.3052 \\
\hline Concentrate- palate weight & 0.76 & 0.4478 & 0.64 & 0.5229 & -0.17 & 0.8619 \\
\hline Complex & 0.07 & 0.9469 & 0.22 & 0.8234 & 2.59 & 0.0102 \\
\hline Familiar & 0.77 & 0.4414 & 0.78 & 0.4336 & 2.49 & 0.0133 \\
\hline Liking & 1.06 & 0.2885 & 1.96 & 0.0511 & 0.06 & 0.9524 \\
\hline
\end{tabular}

Italics indicates predictors significant at $\mathrm{P}=5 \%$ level.

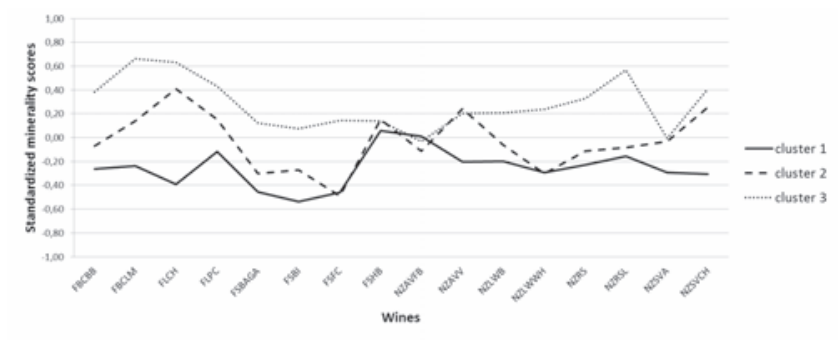

Figure 2. Average minerality ratings as a function of wine $(\mathrm{X}$ axis) for the three participant clusters.

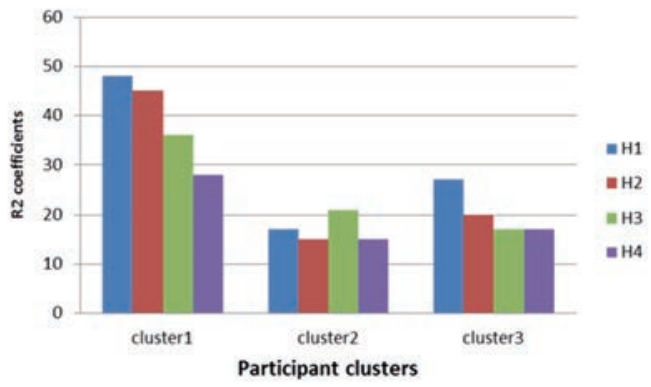

Figure $3 . \mathrm{R}^{2}$ coefficient obtained from the multiple regression analyses of minerality as a function of participant cluster and tested hypothesis. $\mathrm{Y}$ axis=\% variance explained by each regression model $\left(\mathbf{R}^{2}\right)$. 
of Cluster 1, minerality was positively correlated with citrus, flinty/smoky and chalky/calcareous, while negatively correlated with sweetness. For participants of Cluster 2 (more French participants), the main positive predictors of minerality were citrus and bitterness, and the main negative predictor was sweetness. For participants of Cluster 3 (more NZ participants), minerality was positively correlated with citrus, flinty/smoky, chalky/calcareous, complexity, and familiarity, while negatively correlated with Sauvignon varietal characteristics of green and passion fruit.

\section{Sources of perceived minerality}

Figure 3 shows the proportion of variance explained by each of the four plausible hypotheses underlying the evaluation of minerality for each cluster of participants. Minerality judgments of participants from Cluster 1 are better predicted by the four models used in the multiple regression analyses than are minerality judgments of participants from the other two clusters. However, the fourth hypothesis, namely absence of Sauvignon varietal flavor, appears less probable for this group of participants $\left(\mathrm{R}^{2}<30 \%\right)$. The more probable hypotheses for this group of participants are $\mathrm{Hl}$ (stone-related descriptors) and $\mathrm{H} 2$ (reductive notes). For the two other groups, the highest $\mathrm{R}^{2}$ obtained were for $\mathrm{H} 3$ (citrus; fresh/zingy) for Cluster 2 and $\mathrm{H} 1$ (stone-related descriptors) for Cluster 3. Of particular interest is the fact that support for $\mathrm{H} 3$ by Cluster 2 was not driven by perceived acidity/sourness $(\mathrm{t}=-0.98)$ but by citrus $(\mathrm{t}=3.82, \mathrm{P}<0.0002)$ and fresh/zingy $(\mathrm{t}=4.78$, $\mathrm{P}<0.0001$ ). No participant cluster demonstrated evidence that the specific descriptor acidity/sourness was an important predictor of perceived minerality. This result was unexpected, given anecdotal reports from published wine critics concerning the importance of wine acidity to perceived minerality, ${ }^{1}$ and results published recently concerning perceived minerality in Chardonnay wine. ${ }^{4}$ Conceivably, the lack of support for the specific descriptor acidity/sourness as a predictor of perceived minerality could be due to the wine varietal investigated in the current study. That is, as has been reported anecdotally by wine professionals (e.g., reference to a citrus acidity in Sauvignon wines), Sauvignon blanc perceived minerality may be more related to citrus character which was an important predictor for all three clusters in the present study, while minerality in Chardonnay wines from Burgundy may be more dependent on aspects of wine sourness or perceived acidity.

\section{Conclusions}

To summarise, understanding the sensorial reality of perceived minerality as a function of participant culture was the major aim of the work described here. Sensory data demonstrate both cultural similarities and cultural differences in the mental construct mineral as applied to Sauvignon blanc wine. Despite some quantitative differences across cultures in judgment of mineral intensity in the Sauvignon wines, there was relative consistency of sensory responding across the two diverse cultural groups, diverse in terms of wine histories, beliefs and behaviors toward wine ${ }^{5}$ and current styles of Sauvignon blanc production. ${ }^{6}$ This result supports the notion of an agreed sensory experience that gives rise to development of a mental representation that wine tasters label as mineral. Having said that, it is important to note that the between-group variability in minerality intensity judgments to some wines demonstrates that the shared mental representation of mineral character has fuzzy boundaries. ${ }^{7}$ This in turn suggests that caution is required when employing, or interpreting the use of, minerality as a wine descriptor in formal sensory evaluation contexts. Which aspects of wine composition function as the source(s) of this shared mental construct will be reported in a manuscript in progress in which comprehensive physicochemical data collected on the same wines at the time of the sensory study are analyzed and associated with the sensory data.

\section{References}

1. Easton E. Minerality: animal, vegetable or mineral? Available from: http://www. hedrinksbusiness.com/2011/10/mineralityanimal-vegetable-or-mineral/

2. Maltman A. Minerality in wine: a geological perspective. J Wine Res 2013;24:16981.

3. Ross J. Minerality: rigorous or romantic? Practical Winery \& Vineyard Journal 2012;33:50-7.

4. Ballester J, Mihnea M, Peyron D, Valentin D. Exploring minerality of Burgundy Chardonnay wines: a sensory approach with wine experts and trained panellists. Aust J Grape Wine R 2013;19:140-52.

5. Mouret M, Lo Monaco G, Urdapilleta I, Parr WV. Social representations of wine and culture: a comparison between France and New Zealand. Food Qual Prefer 2013;30:102-7.

6. Parr WV, Valentin D, Green JA, Dacremont C. Evaluation of French and New Zealand Sauvignon wines by experienced French wine assessors. Food Qual Prefer 2010;21:56-64.

7. Rosch E. Principals of categorization. In: Rosch E, Lloyd B, eds. Categorization and cognition. Hillsdale, NJ: Erlbaum; 1978. pp 428-79. 